\title{
Limonoids from Citrus reticulata
}

Ashraf T. Khalila ${ }^{\text {* }}$, Galal T. Maatooq ${ }^{\mathrm{a}}$, and Khalid A. El Sayed ${ }^{\mathrm{a}, \mathrm{b}}$

a Department of Pharmacognosy, Faculty of Pharmacy, Mansoura University,

Mansoura 35516, Egypt. E-mail: ashraf-khalil2001@yahoo.com

b Current address: Department of Basic Pharmaceutical Sciences, College of Pharmacy,

University of Louisiana at Monroe, Monroe, Louisiana 71209, USA

* Author for correspondence and reprint requests

Z. Naturforsch. 58c, 165-170 (2003); received August 5/November 18, 2002

The seeds of Citrus reticulata afforded the new limonoid derivative, isolimonexic acid methyl ether, in addition to the the previously isolated limonin, deacetylnomilin, obacunone and ichangin. The structure elucidation was achieved primarily through $1 \mathrm{D}$ and 2-D-NMR analyses. The marginal antimalarial activity of isolimonexic acid methyl ether is reported.

Key words: Citrus, Limonoids, Isolimonexic Acid Methyl Ether

\section{Introduction}

Limonoids comprise a group of highly oxygenated tetracyclic triterpene derivatives, which are widely distributed in plants of Rutaceae and Meliaceae (Champagne et al., 1992; Nakatani, 2001). There are about fifty reported limonoid aglycones, of which thirty-six compounds were isolated from plants of the genus Citrus and related genera (Berhow et al., 2000). These water-insoluble aglycones are usually responsible for the bitter taste of citrus juices. More than seventeen limonoid glycosides were also reported so far. Limonoid glycosides are not bitter in taste and freely soluble in water. Beside their economic importance in the processing of citrus fruits, limonoids have a wide array of interesting biological activities. Limonoids are gaining more current interest as potential anticancer agents. Limonoids are reported to inhibit chemically-induced tumorigenesis formation in the mouth, stomach, small intestine, colon, lung, and skin of experimental animals (Champagne et al., 1992; Berhow et al., 2000). They also reported to inhibit proliferation of breast cancer cells in vitro (Berhow et al., 2000) and moult activity in mosquito Culex quinquefasciatus larvae (Jayaprakasha et al., 1997). Obacunone and limonin, the known citrus limonoids, were recently reported to inhibit azomethane-induced colon carcinogenesis in rats (Tanaka et al., 2000). Limonoids also induce GST, a detoxifying enzyme in mice and rats. Limonoids were reported active as insect repellents and antifeedants and they also disrupt insects' growth and inhibit their reproduction (Ber- how et al., 2000). The present communication describes the isolation of the new natural product isolimonexic acid methyl ether (5) from the seeds of Citrus reticulata, along with the known limonin (1), deacetylnomilin (2), obacunone (3) and ichangin (4). In addition, their antibacterial, antifungal activities are reported along with their effect on Plasmodium falciparum.

\section{Experimental}

\section{General experimental procedure}

Melting points (uncorrected) were obtained using an Electrothermal 9100 instrument; UV spectra were obtained in $\mathrm{MeOH}$ using a Shimadzu UV-1601PC spectrophotometer; IR spectra as $\mathrm{KBr}$ disks on a Perkin-Elmer 8508 spectrophotometer; NMR spectra were recorded in DMSO- $d_{6}$ on a Bruker AMX-NMR spectrometer, operating at $500 \mathrm{MHz}$ for ${ }^{1} \mathrm{H}-\mathrm{NMR}$ and $125 \mathrm{MHz}$ for ${ }^{13} \mathrm{C}$ NMR. The HRFTMS data were measured using a Bioapex FT-ICR mass spectrometer with electrospray ionization.

\section{Plant material}

Mandarin fruits (Citrus reticulata, Rutaceae) were purchased from Mansoura district in January 1999, identified by Prof. Nabil R. Samrah, Prof. of Pomology, Faculty of Agriculture, Mansoura University, Mansoura, Egypt. A voucher specimen is kept at the Dept. of Pharmacognosy, Faculty of Pharmacy, Mansoura, Egypt. 


\section{Extraction and isolation}

Seeds were collected, dried and powdered. The powdered seeds $(1.9 \mathrm{~kg})$ were exhaustively extracted with ethanol. The alcoholic extract was evaporated in vacuo to afford $495 \mathrm{~g}$. The latter was defatted with light petroleum (b.p. 60-80) to afford a non-polar fraction $(108 \mathrm{~g})$ and a polar fraction (387 g.). The latter was dissolved in $500 \mathrm{ml}$ water and extracted with ethyl acetate, which was evaporated in vacuo. The resinous ethyl acetate extract ( $22 \mathrm{~g}$ ) was column chromatographed over Silica gel $(300 \mathrm{~g})$ column $(3.5 \times 90 \mathrm{~cm})$. The column was gradiently eluted with $\mathrm{CH}_{2} \mathrm{Cl}_{2}$-acetone mixture and fractions were monitored by TLC using pre-coated Silica gel $\mathrm{GF}_{254}$ (Merck) and the same previous mixture of solvents for development. Spots were visualized by spraying with vanillin $/ \mathrm{H}_{2} \mathrm{SO}_{4}$ followed by heating at $105^{\circ} \mathrm{C}$ for $30 \mathrm{sec}$, a procedure which gave invariably reddishbrown spots. Fractions containing a major compound with $\mathrm{R}_{\mathrm{f}} 0.98\left(10 \%\right.$ acetone in $\left.\mathrm{CH}_{2} \mathrm{Cl}_{2}\right)$ were evaporated to dryness to give $550 \mathrm{mg}$ which were further purified by C. C. (Silica gel) with isocratic elution with $\mathrm{CH}_{2} \mathrm{Cl}_{2}$ containing $0.01 \%$ acetic acid to afford compound $\mathbf{3}(30 \mathrm{mg})$. Fractions showing a spots at $\mathrm{R}_{\mathrm{f}} 0.8$ were evaporated in vacuo to give $3.2 \mathrm{~g}$ of impure crystalline residue. Repeated C. C. purification of $0.2 \mathrm{~g}$ of the latter residue afforded $100 \mathrm{mg}$ of compound 1. Fractions containing one spot with $\mathrm{R}_{\mathrm{f}} 0.40\left(10 \%\right.$ acetone in $\left.\mathrm{CH}_{2} \mathrm{Cl}_{2}\right)$ were evaporated and crystallized to afford $20 \mathrm{mg}$ of colorless needles (compound 2). Fractions containing one spot with $\mathrm{R}_{\mathrm{f}} 0.32\left(10 \%\right.$ acetone in $\left.\mathrm{CH}_{2} \mathrm{Cl}_{2}\right)$ were evaporated and crystallized to afford $10 \mathrm{mg}$ of colorless needles (compound 5). Fractions containing one spot with $\mathrm{R}_{\mathrm{f}} 0.22(10 \%$ acetone in $\mathrm{CH}_{2} \mathrm{Cl}_{2}$ ) were evaporated and crystallized to afford $30 \mathrm{mg}$ of colorless needles (compound 4).

Limonin (1): $\mathrm{mp} 118-120^{\circ} \mathrm{C} ;[\alpha]_{\mathrm{D}}^{25}-1.1^{\circ}(c$ 1.21, acetone); FABMS, $[\mathrm{M}+\mathrm{H}]^{+}$at $\mathrm{m} / z$ 471, $\mathrm{C}_{26} \mathrm{H}_{30} \mathrm{O}_{8}$; IR $v_{\max }(\mathrm{KBr}) 3154,2960,1761$ (lactones), $1719(\mathrm{C}=\mathrm{O}), 1647,1503,1285,1030$, $875 \mathrm{~cm}^{-1} .{ }^{1} \mathrm{H}-\mathrm{NMR}\left(500 \mathrm{MHz}, \mathrm{DMSO}-d_{6}\right): \delta 4.10$ (br s, H-1), 2.26 ( $d d, J=14.8,3.2 \mathrm{~Hz}, \mathrm{H}-2 \mathrm{a}), 2.65$ $(d d, J=14.8,3.2 \mathrm{~Hz}, \mathrm{H}-2 \mathrm{~b}), 2.47(d d, J=15.0$, $2.8 \mathrm{~Hz}, \mathrm{H}-5), 2.75$ (dd, $J=15.0,2.8 \mathrm{~Hz}, \mathrm{H}-6 \mathrm{a}), 3.10$ $(t, J=15.0 \mathrm{~Hz}, \mathrm{H}-6 \mathrm{~b}), 2.55(d d, J=10.0,2.0 \mathrm{~Hz}$, H-9), 1.78 ( $m, \mathrm{H}-11 \mathrm{a}), 1.70$ ( $m, \mathrm{H}-11 \mathrm{~b}), 1.26$ ( $m$, H-12a), 1.73 (m, H-12b), 4.09 ( $s, \mathrm{H}-15), 5.45$ ( $s$,
H-17), 1.09 (3H, s, H-18), 4.46 (d, $J=13 \mathrm{~Hz}, \mathrm{H}-19 \mathrm{a})$, $4.90(d, J=13 \mathrm{~Hz}, \mathrm{H}-19 \mathrm{~b}), 7.63$ (br s, H-21), 6.48 (br s, H-22), 7.69 (br s, H-23), 0.98 (s, H-24), 1.17 (3H, $s, \mathrm{H}-25), 1.01$ (3H, $s, \mathrm{H}-26),{ }^{13} \mathrm{C}-\mathrm{NMR}$, data for compounds $\mathbf{1 - 5}$ are listed in Table I.

Deacetylnomilin (2): $\mathrm{mp} 253-255^{\circ} \mathrm{C}$ dec; $[\alpha]_{\mathrm{D}}^{25}$ - 2.7 $7^{\circ}$ c 1.20, acetone); IR $v_{\max }(\mathrm{KBr}) 3400,3000-$ 2900, 1770-1700 (lactone and $\mathrm{C}=\mathrm{O}$ ), 1460, 1390, 1290, 1120, 1080, 1030, $870 \mathrm{~cm}^{-1} .{ }^{1} \mathrm{H}-\mathrm{NMR}$ $\left(500 \mathrm{MHz}, \mathrm{DMSO}-d_{6}\right): \delta 3.63(t, \mathrm{H}-1), 2.98(t, J=$ $2.0 \mathrm{~Hz}, \mathrm{H}-2 \mathrm{a}), 3.30$ (dd, $J=14.0,2.0 \mathrm{~Hz}, \mathrm{H}-2 \mathrm{~b}), 2.42$ $(d d, J=15.0,2.8 \mathrm{~Hz}, \mathrm{H}-5), 2.28(d d, J=15.0,2.8 \mathrm{~Hz}$, H-6a), 2.65 ( $t, J=15.0 \mathrm{~Hz}, \mathrm{H}-6 \mathrm{~b}), 2.67$ ( $d d, J=10.0$, $2.0 \mathrm{~Hz}, \mathrm{H}-9), 1.40$ ( $m, \mathrm{H}-11 \mathrm{a}), 1.67$ ( $m, \mathrm{H}-11 \mathrm{~b}), 1.70$ ( $m, \mathrm{H}-12 \mathrm{a}), 1.73$ ( $m, \mathrm{H}-12 \mathrm{~b}), 3.75$ ( $s, \mathrm{H}-15), 5.35$ ( $s$, $\mathrm{H}-17), 1.98$ (3H, s, H-18), 1.12 ( $s, \mathrm{H}-19), 7.62$ (br s, H-21), 6.65 ( $b r s, \mathrm{H}-22), 7.71$ (br $s, \mathrm{H}-23), 1.09$ ( $s$, $\mathrm{H}-24), 1.26$ (3H, s, H-25), 1.44 (3H, $s, \mathrm{H}-26)$.

Obacunone (3), mp $212-215^{\circ} \mathrm{C}$; IR $v_{\max }(\mathrm{KBr})$ 3400, 3000-2900, 1754 (lactone), 1711 ( $\mathrm{C}=\mathrm{O})$, 1460, 1290, 1160, $880 \mathrm{~cm}^{-1}$. ${ }^{1} \mathrm{H}-\mathrm{NMR} \quad(500 \mathrm{MHz}$, DMSO- $\left.d_{6}\right): \delta 6.70(d, J=11.8 \mathrm{~Hz}, \mathrm{H}-1), 5.81(d, J=$ $11.8 \mathrm{~Hz}, \mathrm{H}-2), 2.66(d d, J=13.5,5.0 \mathrm{~Hz}, \mathrm{H}-5), 2.20$ $(d d, J=13.8,4.8 \mathrm{~Hz}, \mathrm{H}-\mathrm{H}-6 \mathrm{a}), 3.02(t, J=14.0 \mathrm{~Hz}$, H-6b), 2.10 ( $d d, J=10.0,2.0 \mathrm{~Hz}, \mathrm{H}-9), 1.70(m$, H-11a), 1.77 ( $m, \mathrm{H}-11 \mathrm{~b}), 1.77$ ( $m, \mathrm{H}-12 \mathrm{a}), 1.80$ ( $m$, $\mathrm{H}-12 \mathrm{~b}), 3.75$ ( $s, \mathrm{H}-15), 5.41$ ( $s, \mathrm{H}-17), 0.99$ (3H, $s$, H-18), 1.34 (3H $s, \mathrm{H}-19), 7.63$ (br s, H-21), 6.48 (br $s, \mathrm{H}-22), 7.70$ (br s, H-23), 1.14 (3H, s, H-24), 1.30 $(3 \mathrm{H}, s, \mathrm{H}-25), 1.38(3 \mathrm{H}, s, \mathrm{H}-26)$.

Ichangin (4), mp $198-199^{\circ} \mathrm{C} ;[\alpha]_{\mathrm{D}}^{25}-6.3^{\circ}$ (c 1.21 acetone); IR $v_{\max }(\mathrm{KBr}) 3100-3600$ br, 2940, $1760-$ $1700 \mathrm{br}, 1280,1030,868 \mathrm{~cm}^{-1} .{ }^{1} \mathrm{H}-\mathrm{NMR}(500 \mathrm{MHz}$, DMSO- $\left.d_{6}\right): \delta 3.80$ ( $\left.m, \mathrm{H}-1\right), 2.60$ ( $\left.m, \mathrm{H}-2 \mathrm{a}\right), 2.72$ (dd, $J=13,9.5 \mathrm{~Hz}, \mathrm{H}-2 \mathrm{~b}), 2.61$ ( $m, \mathrm{H}-5), 2.20$ (dd, $J=13.5,2.0 \mathrm{~Hz}, \mathrm{H}-6 \mathrm{a}), 2.85$ ( $t, J=13.5 \mathrm{~Hz}, \mathrm{H}-6 \mathrm{~b})$, $2.18(d d, J=9.8,1.0 \mathrm{~Hz}, \mathrm{H}-9), 3.69(s, \mathrm{H}-15), 5.38$ $(s, \mathrm{H}-17), 0.98(3 \mathrm{H}, s, \mathrm{H}-18), 4.65(d \mathrm{~d}, J=13.0 \mathrm{~Hz}$, H-19-a), 4.90 ( $d, J=13.0 \mathrm{~Hz}, \mathrm{H}-19 \mathrm{~b}), 7.60$ (br $s$, $\mathrm{H}-21), 6.40$ (br s, H-22), 7.65 (br s, H-23), 1.15 (3H, $s, \mathrm{H}-24), 1.18$ (3H, s, H-25), 1.10 (3H, s, H-26).

Isolimonexic acid methyl ether (5), $\mathrm{C}_{27} \mathrm{H}_{32} \mathrm{O}_{10}$; HRFTMS $m / z$ calcd for $\mathrm{C}_{27} \mathrm{H}_{33} \mathrm{O}_{10}(\mathrm{M}+\mathrm{H})^{+}$ 517.2074 , found 517.2012; $\mathrm{mp}, 166-167^{\circ} \mathrm{C} ;[\alpha]_{\mathrm{D}}^{25}$ - 4.1 ${ }^{\circ}$ ( $c$ 0.22, methanol); UV $\lambda_{\max }(\log \varepsilon)(\mathrm{MeOH})$ 205 (4.01), 269 (2.54), 275 (2.56) nm; IR $v_{\max }(\mathrm{KBr})$, 3150, 2950, 1761-1719 br strong, 1290, 1120, $1030 \mathrm{~cm}^{-1} .{ }^{1} \mathrm{H}-\mathrm{NMR}\left(500 \mathrm{MHz}, \mathrm{DMSO}-d_{6}\right): \delta 4.11$ (br s, H-1), 2.26 ( $d d, J=14.8,3.2 \mathrm{~Hz}, \mathrm{H}-2 \mathrm{a}), 2.65$ (dd, $J=14.8,3.2 \mathrm{~Hz}, \mathrm{H}-2 \mathrm{~b}), 2.49$ ( $m, \mathrm{H}-5), 2.99$ ( $m$, 


\begin{tabular}{|c|c|c|c|c|c|}
\hline $\mathrm{C} \#$ & 1 & 2 & 3 & 4 & 5 \\
\hline 1 & 78.8 & 68.4 & 158.8 & 70.3 & 78.3 \\
\hline 2 & 36.1 & 39.2 & 122.3 & 38.2 & 35.6 \\
\hline 3 & 170.3 & 170.8 & 167.6 & 171.5 & 170.1 \\
\hline 4 & 79.5 & 83.8 & 84.7 & 71.7 & 83.8 \\
\hline 5 & 58.4 & 49.4 & 56.6 & 49.6 & 48.5 \\
\hline 6 & 36.6 & 38.9 & 40.2 & 39.0 & 36.1 \\
\hline 7 & 208.1 & 208.7 & 209.1 & 209.5 & 207.8 \\
\hline 8 & 50.3 & 52.0 & 53.0 & 52.1 & 50.2 \\
\hline 9 & 46.9 & 43.7 & 48.9 & 48.9 & 46.3 \\
\hline 10 & 45.3 & 44.2 & 43.5 & 46.3 & 45.2 \\
\hline 11 & 19.7 & 16.7 & 19.6 & 21.4 & 17.7 \\
\hline 12 & 29.3 & 31.2 & 32.4 & 32.8 & 28.7 \\
\hline 13 & 37.7 & 36.8 & 37.7 & 36.3 & 37.8 \\
\hline 14 & 64.9 & 65.8 & 66.2 & 65.2 & 66.1 \\
\hline 15 & 54.1 & 52.6 & 53.5 & 52.0 & 52.6 \\
\hline 16 & 167.4 & 167.2 & 167.9 & 166.9 & 167.2 \\
\hline 17 & 77.9 & 77.5 & 78.3 & 77.4 & 77.6 \\
\hline 18 & 17.6 & 20.2 & 21.3 & 20.6 & 19.7 \\
\hline 19 & 66.7 & 15.9 & 17.1 & 67.8 & 64.8 \\
\hline 20 & 120.3 & 120.2 & 120.9 & 120.1 & 161.5 \\
\hline 21 & 143.4 & 143.3 & 144.2 & 143.4 & 103.1 \\
\hline 22 & 110.2 & 110.2 & 111.1 & 110.2 & 123.1 \\
\hline 23 & 141.7 & 141.6 & 142.5 & 141.5 & 168.7 \\
\hline 24 & 17.1 & 16.1 & 17.2 & 15.7 & 16.4 \\
\hline 25 & 29.8 & 33.0 & 32.5 & 32.7 & 29.6 \\
\hline 26 & 21.4 & 23.1 & 27.4 & 26.1 & 21.4 \\
\hline$-\mathrm{OCH}_{3}$ & & & & & 56.6 \\
\hline
\end{tabular}

Table I. ${ }^{13} \mathrm{C}-\mathrm{NMR}$ Data of the isolated limonoids. $^{a}$

In DMSO- $d_{6}, 125 \mathrm{MHz}$. Carbon multiplicities were determined by DEPT $135^{\circ}$ experiments.

Hz, H-6a), 3.12 ( $t, J=15.0 \mathrm{~Hz}, \mathrm{H}-6 \mathrm{~b}), 2.50$ ( $d d, J=$ 10.0, 2.0 Hz, H-9), 3.81 (s, H-15), 5.10 (s, H-17), 1.09 (3H, s, H-18), 4.42 (d, $J=13.0 \mathrm{~Hz}, \mathrm{H}-19-\mathrm{a}), 4.92$ (d, $J=13.0 \mathrm{~Hz}, \mathrm{H}-19 \mathrm{~b}), 5.96$ (br s, H-21), 6.39 (br s, H22), 1.12 (s, H-24), 1.44 (3H, s, H-25), 0.98 (3H, $s$, $\mathrm{H}-26), 3.45\left(3 \mathrm{H}, s,-\mathrm{OCH}_{3}\right)$.

\section{Anti-malarial activity}

Stock cultures of the Sierra Leone D6 clone (chloroquine-sensitive, mefloquine-resistant) and Indochina W2 clone (chloroquine-resistant, mefloquine-sensitive) were obtained from the Department of Pharmacognosy, University of Mississippi culture collection and maintained using a modification of Trager and Jensen (1976). The detailed methodology is reported by El Sayed et al. (1996).

\section{Results and Discussion}

The alcoholic extract of the seeds of Citrus reticulatea afforded a bitter-tasting mixture whose components gave an Ehrlich-positive reaction on TLC, which is characteristic of limonoids (Bennett and Herman, 1989). Column chromatographic fractionation of the crude mixture resulted in the isolation of five pure compounds $\mathbf{1 - 5}$ (Fig. 1). Compound 1 revealed a molecular ion $[\mathrm{M}+\mathrm{H}]^{+}$ at $m / z=471$ equivalent to the molecular formula $\mathrm{C}_{26} \mathrm{H}_{30} \mathrm{O}_{8}$ and 12 degrees of unsaturation (DBE). Spectral data of $\mathbf{1}$ indicated the presence of 2 lactones, one ketone, 4 methyls and a furan ring. All physical and spectral data were consistent with those reported for limonin (Dreyer et al., 1976). Compound 2 revealed a molecular formula $\mathrm{C}_{26} \mathrm{H}_{32} \mathrm{O}_{8}$ and 11 DBE units, suggesting one ring less than limonin. NMR data of $\mathbf{2}$ possessed the same features of $\mathbf{1}$ except for the replacement of C-1 methine signal at $\delta 78.8$ and C-19 methylene signal at $\delta 66.7$ with the methine signal at $\delta 68.4$ and the methyl carbon at $\delta 15.9$, respectively. In the HMQC, the latter 2 signals were correlated to the proton triplet at $\delta 3.63$ and the methyl singlet at $\delta 1.12$, respectively. On the other hand, the HMBC spectrum of $\mathbf{2}$ showed cross peak correlations between $\mathrm{H}-1$ and the quaternary C-3 carbonyl ( $\delta$ 170.8) and C-10 ( $\delta$ 44.2). The methyl singlet $\mathrm{H}_{3}-19$ also show HMBC correlations with $\mathrm{C}-1$, 


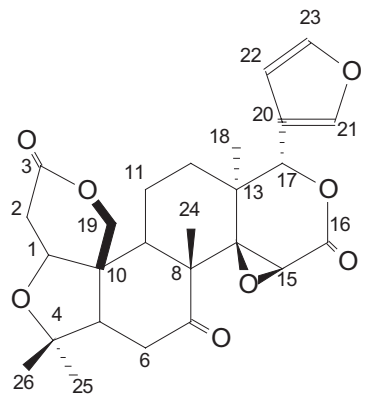

1 Limonin

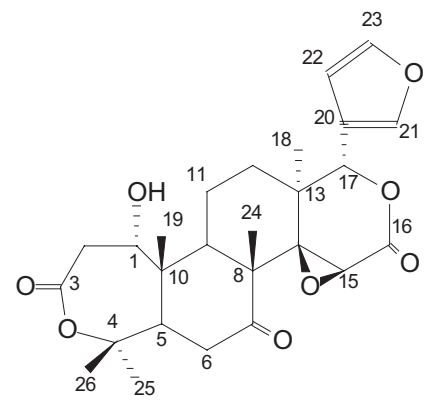

2 Deacetylnomilin

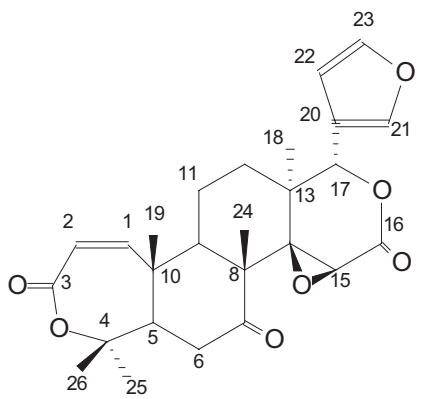

3 Obacunone

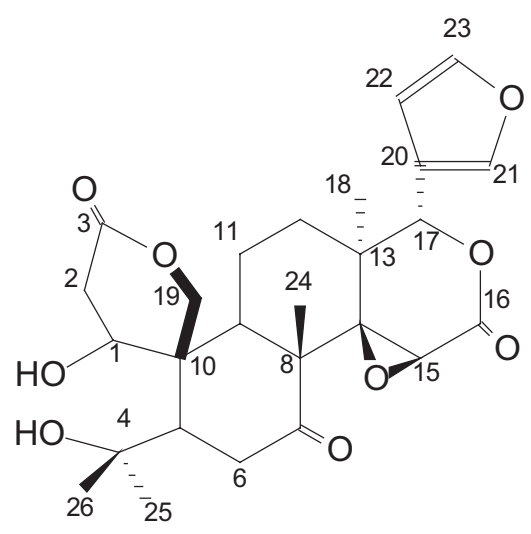

\section{Ichangin}

Fig. 1. Limonoids from Citrus reticulata.

C-5, C-9, and C-10. Consequently, the structure of 2 was determined to be deacetylnomilin (Bennett and Hasegawa, 1981). Compound $\mathbf{3}$ possessed a molecular formula of $\mathrm{C}_{26} \mathrm{H}_{30} \mathrm{O}_{7}$, i.e., 18 Daltons less than 2 (probably due to loss of $\mathrm{H}_{2} \mathrm{O}$ unit). The ${ }^{13} \mathrm{C}$-NMR spectrum of compound $\mathbf{3}$ was similar to that of 2 except for the formation of $\Delta^{1,2}$ system. The olefinic methine signals at $\delta 158.8$ and 122.3, which showed cross peaks at $\delta 6.70(\mathrm{~d}, J=11.8)$ and $5.81(\mathrm{~d}, J=11.8)$ in the HMQC spectrum were assigned to $\mathrm{C}-1$ and $\mathrm{C}-2$, respectively. This was confirmed by HMBC correlations between $\mathrm{H}-1$ and both C-3 ( $\delta$ 167.6) and C-19 ( $\delta$ 17.1). Meanwhile, $\mathrm{H}-2$ doublet showed HMBC correlation with

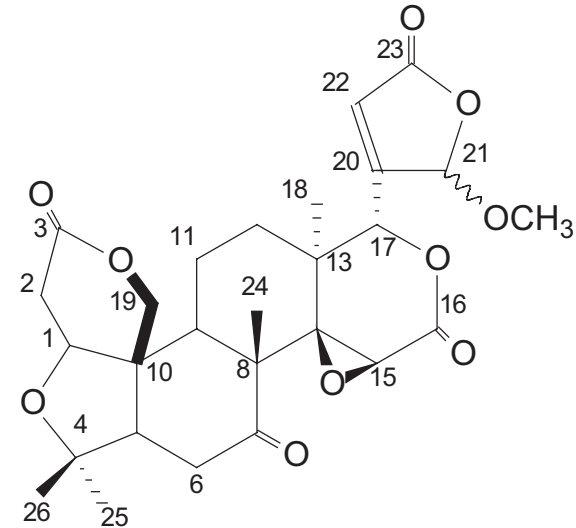

5 Isolimonexic acid methyl ether
C-10 ( $\delta$ 43.5). These data were in full agreement to those reported for obacunone (Dreyer et al., 1976).

Compound 4 revealed $[\mathrm{M}+\mathrm{H}]^{+}$at $m / z 489$ equivalent to the molecular formula $\mathrm{C}_{26} \mathrm{H}_{32} \mathrm{O}_{9}$ and 11 degrees of unsaturation, i.e., with 18 mass units more than that of limonin. The ${ }^{13} \mathrm{C}-\mathrm{NMR}$ data of 4 indicated an upfield shifts of C-1 ( $8.5 \mathrm{ppm})$ and C-4 (7.8 ppm), compared with those of limonin. These data suggested that the ether linkage between C-1 and C-4 was opened. Comparison of the data of $\mathbf{4}$ and those of Ichangin (Bennett et al., 1991) revealed that the two compounds are identical.

The HR-FTMS of compound 5 revealed a molecular ion peak $[\mathrm{M}+\mathrm{H}]^{+}$at $m / z$ 517.2012, sug- 
gesting the molecular formula $\mathrm{C}_{27} \mathrm{H}_{32} \mathrm{O}_{10}$ and 12 DBE units. The NMR spectral data of $\mathbf{5}$ were somewhat similar to those of limonin except for the furan moiety which is replaced in case of 5 by a 5-methoxy-2(5H)-furanone moiety. The HMQC data of 5 exhibited a proton singlet at $\delta 3.45$, which is correlated with the methyl carbon at $\delta 56.6$, indicating the presence of a methoxyl group. This methoxy singlet showed ${ }^{3} J$-HMBC correlation with the methine carbon at $\delta 103.1$, which in turn was correlated with the proton singlet at $\delta 5.96$ and was assigned to C-21. The proton $\mathrm{H}-21$ showed ${ }^{3} J$ HMBC correlation with the olefinic methine carbon at $\delta 123.1$ (correlated with the broad proton singlet at $\delta$ 6.39), assigned to C-22. Both $\mathrm{H}-21$ and $\mathrm{H}-22$ showed ${ }^{3} J$ - and ${ }^{2} J$-HMBC correlations, respectively, with the quaternary carbonyl signal at $\delta$ 168.7, which was assigned to $\mathrm{C}-23$. The proton singlet of H-17 ( $\delta 5.10)$ showed ${ }^{3} J$-HMBC correlation with H-22 ( $\delta 6.39)$ and ${ }^{2} J-H M B C$ correlation with the quaternary carbon at $\delta 161.5$, assigned to $\mathrm{C}-20$. The downfield shifting of the carbon C-20 indicated its $\beta$-location to the carbonyl C-23, and hence confirmed the assigned isolimonexic acid skeleton rather than limonexic acid at which the carbonyl is at C-21 and the methoxy is at C-23. The splitting pattern and the lack of any DQFCOSY correlation between $\mathrm{H}-21$ and $\mathrm{H}-22$ further supported this fact (Lee et al., 1999 and Ming et al., 1987). The stereochemistry of the chiral center C-21 was left ambiguous since there was no enough NOESY data to support its assignment. It is worth noting that X-ray crystallography of the naturally occurring limonexic acid, reported from Citrus nippokoreana, usually occurs as a $23 S$ and $23 R$ epimeric mixture (Lee et al., 1999). The natural identity of $\mathbf{5}$ was confirmed by TLC detection of this compound in the fresh seed ethanolic extract. This is further supported by the fact that limonexic acid was isolated from a natural source in which limonin was not detected by TLC, suggesting that these compounds exist in nature and are not artifacts due to oxidation of limonin (Lee et al., 1999). Based on the fore-mentioned data, compound $\mathbf{5}$ was found to be isolimonexic acid methyl ether, a newly reported natural product.

All limonoids $\mathbf{1 - 5}$ were subjected to antifungal activities against Candida albicans (ATCC 90028) and Cryptococcus neoformans (ATCC 90113), and antibacterial against Staphylococcus aureus (ATCC 29213), Pseudomonas aeruginosa (ATCC 27853) and Bacillus subtilis (ATCC 6633) and found inactive at a concentration of $500 \mu \mathrm{g} / \mathrm{ml}$. Of all tested limonins, isolimonexic acid methyl ether (5) showed marginal activity against Plasmodium falciparum (D6 clone) and P. falciparum (W2 clone) with $\mathrm{IC}_{50}>4.76 \mu \mathrm{g} / \mathrm{ml}$, with selectivity index $>1$ and without any cytotoxicity to Vero cells (Vero African Green Monkey kidney cells ATCC CCL 81).

\section{Acknowledgment}

Dr. D. Chuck Dunbar, The National Center for Natural Products Research, University of Mississippi, is acknowledged for recording NMR and HRMS analysis. 
Bennett R. D., and Hasegawa S. (1981), Limonoids of calamondin seeds. Tetrahedron 37, 17-24.

Bennett R. D., and Herman Z. (1989), Glucosides of acidic limonoids in Citrus. Phytochemistry 28, $2777-$ 2781.

Bennett R. D., Miyake M., Ozaki Y., and Hasegawa S. (1991), Limonoids glucosides in Citrus aurantium. Phytochemistry 30, 3803-3805.

Berhow M. A., Hasegawa S., and Manners G. D. (2000), Citrus Limonoids - Functional Chemicals in Agriculture and Food. Berhow and Hasegawa, American Chemical Society, Washington DC.

Champagne D. E., Koul O., Isman M. B., Scudder G. E., and Towers G. H. N. (1992), Biological activity of limonoids from Rutales. Phytochemistry 31, 377394.

Dreyer D. L., Bennett R. D., and Basa S. C. (1976), Limonoids from Atalantia monophylla, isolation and structure. Tetrahedron 32, 2367-2373.

El Sayed K. A., Dunbar, D. C., Goins D. K., Cordova C. R., Perry T. L., Wesson K. J., Sanders S. C., Janus, S. A., and Hamann M. T. (1996), The marine environment: A resource for prototype antimalarial agents. J. Nat. Toxins 5, 261-285.
Jayaprakasha G. K., Singh R. P., Pereira J., and Sakariah K. K. (1997), Limonoids from Citrus reticulata and their moult inhibiting activity in mosquito Culex quinquefasciatus larvae. Phytochemistry 44, 843-846.

Lee S.-Y., Morita H., Takeya K., Itokawa H., and Fukaya H. (1999), Limonoids from Citrus nippokoreana Nat. Med. 53, 255-258.

Ming K., Gray A. I., and Waterman P. G. (1987), Limonoids, alkaloids, and a coumarin from the root and stem barks of Tetradium glabrifolium. J. Nat. Prod. 50, $1160-1163$.

Nakatani M. (2001), Bioactive Compounds from Natural Sources (Corrado Tringali, ed.). Taylor \& Francis, London and New York.

Quader A., Put P. H., Gray A. I., Hartley T., Hu Y., and Waterman P. G. (1990), Alkaloids and limonoids of Tetradium trichotomum: chemotaxonomic significance. Biochem. Syst. Ecol. 18, 251-252.

Tanaka T., Kohno H., Tsukio Y., Honjo S., Tanino M., Miyake M., and Wada K. (2000), Citrus limonoids obacunone and limonin inhibit azomethane-induced colon carcinogenesis in rats. Biofactors 13, 213-218.

Trager W., and Jensen J. B. (1976), Human malaria parasites in continuous culture. Science 193, 673-675. 